\title{
Macular Hole Formation After Intravitreal Ranibizumab Injection in Wet Age-Related Macular Degeneration
}

\author{
Chandoshi Mukherjee*, Arijit Mitra, N. Ajith Kumar, Samer Elsherbiny and Peck Lin Lip
}

The Birmingham and Midland Eye Centre, City Hospital Dudley Road Birmingham, West Midlands B18 7QH, UK

\begin{abstract}
Ranibizumab is a monoclonal antibody fragment that inhibits angiogenesis by inhibiting vascular endothelial growth factor A, used as a treatment for patients with wet aged-related macular degeneration (ARMD). Adverse effects from intravitreal Ranibizumab injections are well recognised. Macular hole formation following Ranibizumab injection is a complication that has been recently reported in few case reports. We present a larger case series of five patients, who developed full thickness macular holes (FTMH) after intravitreal Ranibizumab injections for treatment of wet ARMD that we were aware of between 2009 and 2013.
\end{abstract}

Keywords: Full thickness macular hole, intravitreal ranibizumab injection, pigment epithelial detachment, posterior vitreous traction, wet age-related macular degeneration.

\section{INTRODUCTION}

Ranibizumab is a monoclonal antibody fragment that inhibits angiogenesis by inhibiting vascular endothelial growth factor A, used as a treatment for patients with wet aged-related macular degeneration (ARMD). Adverse effects from intravitreal Ranibizumab injections are well recognised [1-3]. Macular hole formation following Ranibizumab injection is a complication that has been recently reported in few case reports. We present a larger case series of five patients, who developed full thickness macular holes (FTMH) after intravitreal Ranibizumab injections for treatment of wet ARMD that we were aware of between 2009 and 2013.

\section{CASE REPORTS}

\section{Case 1}

An 81 year-old-male was treated with three to four weekly Ranibizumab injections for right eye (OD) vascularised pigment epithelial detachment (PED) with no evidence of pre-existing vitreo-macular traction (VMT) on initial optical coherence tomography (OCT) scan. The presenting visual acuity (VA) was 6/30 OD. One month after his last treatment, his VA was reduced to 6/60 OD and OCT showed a stage 3 FTMH with resolved PED. Following successful macular hole surgery and subsequent cataract surgery, his post-operative vision improved to 6/24 OD.

\section{Case 2}

A 62 year-old female was treated with three to four weekly intravitreal Ranibizumab injections for left eye (OS)

*Address correspondence to this author at the Birmingham and Midland Eye Centre, City Hospital Dudley Road Birmingham, West Midlands, B18 7QH, UK; Tel: +44 7973722247; E-mail: mukherjee.rhea0@gmail.com occult subfoveal choroidal neovascular membrane (CNVM) with pre-existing focal VMT noted before treatment. The presenting VA was 6/24 OS. One month after her last treatment, a stage $3 \mathrm{FTMH}$ was noted with VA reduced to $2 / 60$. Following successful macular hole surgery the vision in the left eye improved to $6 / 36$.

\section{Case 3}

A 62 year-old female, who received four weekly Ranibizumab injections to both eyes for vascularised large PED, was referred to our vitreoretinal clinic with a FTMH in her right eye one month after last injection. The VA in the right eye was $6 / 60$ on presentation to us with OCT showed FTMH. There was no information on pre-existing VMT before Ranibizumab injection. She refused surgery due to the guarded prognosis.

\section{Case 4 (Fig. 1)}

An 80 year-old-female was treated with three four-weekly intravitreal Ranibizumab injections, for left eye peripapillary CNVM with subretinal fluid extension. At presentation the VA was 6/60 OS and OCT showed pre-existing focal VMT before injection. Nine months after treatment, her VA remained 6/60 OS and she was noted to have a stage 3 FTMH. She refused operation due to the guarded prognosis.

\section{Case 5 (Fig. 2)}

An 81 year-old female was treated with bilateral Ranibizumab injections for subfoveal CNVM associated with a large dome shaped PEDs. OCT of left eye before injection also showed a partial posterior vitreous detachment (PVD) with broad VMT. After receiving six intravitreal injections, left eye was found to have a stage 3 FTMH with flattened PED and the vision reduced from 6/15 pretreatment to $6 / 60$. She had refused macular hole surgery. 

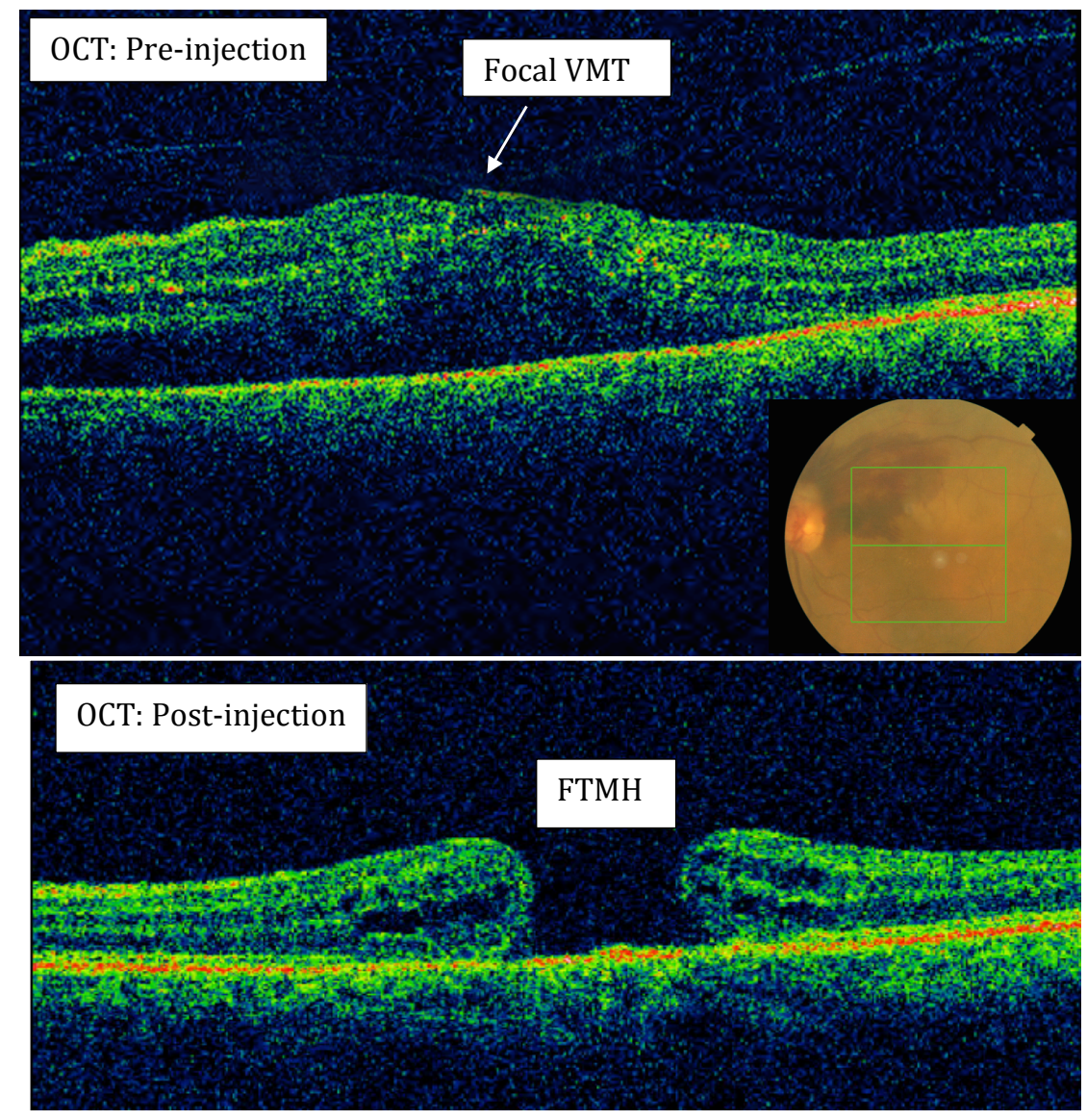

Fig. (1). (Case 4): Full thickness macular hole formation (FTMH) after Ranibizumab injections in a patient with peripapillary choroidal neovascularization with subretinal fluid extension (insert colour fundus photo). Pre-injection OCT showed the presence of pre-existing focal vitreo-macular traction (VMT).

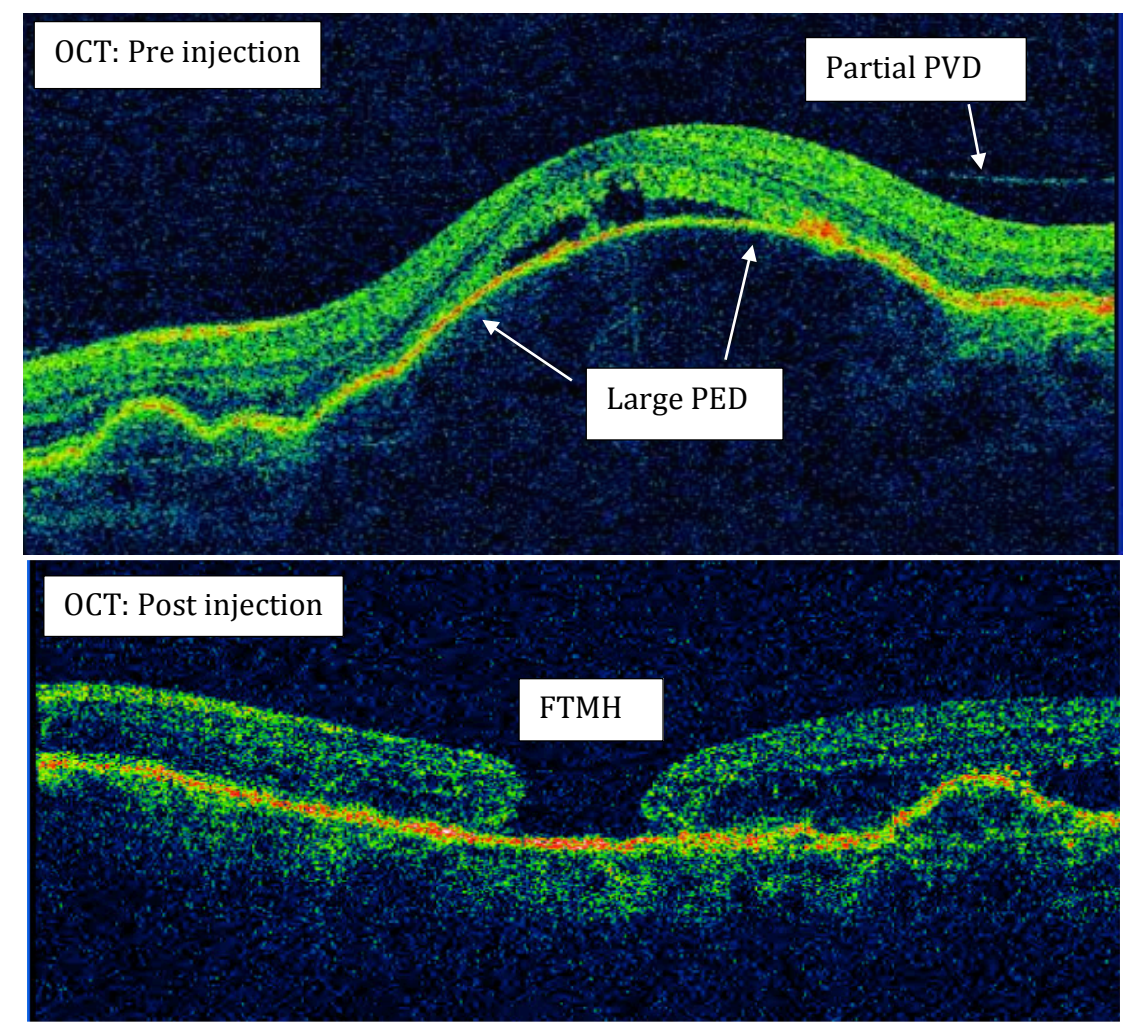

Fig. (2). (Case 5): Full thickness macular hole formation (FTMH) after Ranibizumab injections in a patient with wet AMD and dome shaped PED. Pre-injection OCT showed the beginning of partial posterior vitreous detachment (PVD). 


\section{DISCUSSION}

Deterioration of central vision following intravitreal antivascular endothelial growth factor (anti-VEGF) injections for ARMD, especially in the presence of PED may be commonly due to new macular haemorrhage or retinal pigment epithelial rip. FTMH formation until now has been reported in a few isolated cases [4-8].

The mechanism of idiopathic FTMH formation was hypothesized by Gass as a result of contraction of the prefoveal vitreous cortex, causing focal tangential traction on fovea [9]. Gaudric et al. in an optical coherence tomography (OCT) study concluded that vitreous traction may be oblique [10]. Therefore, both tangential and anterior-posterior transvitreal traction has been implicated in the development of idiopathic FTMH.

Posterior vitreous detachment (PVD) in recent years has been closely speculated to have a potential significant role in the development of FTMH following intravitreal injections. Geck et al. observed a 25\% PVD rate after intravitreal injections within a mean follow-up period of 11 weeks and incidence correlates with increasing age [11]. Querques et al. suggested that intravitreal anti-VEGF might induce vitreous incarceration causing vitreoretinal traction. Contraction of the CNVM may impose forces on the retinal pigment epithelium and the retinal surface resulting in macular hole formation [4]. Chemical compounds applied to the vitreous cavity is also suggested to modify the structure of the vitreous gel, leading to incomplete PVD and traction causing a macular hole [5]. Grigoropoulos et al. hypothesized that intravitreal injections can increase the traction on the fovea by causing vitreous syneresis, globe deformation during needle insertion, and vitreous incarceration at the insertion site. Incomplete PVD, which may be induced by the intravitreal injections may create focal sites of traction on the retinal surface and in the presence of pre-existing VMA, this may increase the chances of FTMH [6]. Our cases support this latter theory as 3 out of 5 cases have evidence of preexisting focal VMT or incomplete PVD before the first injection (VMT grading was based on OCT classification [12]).

In a case report by Cho et al. of FTMH formation after intravitreal Ranibizumab injection for IPCV, the patient underwent prompt macular hole surgery followed by two Ranibizumab injections achieving good result of 6/18 in that eye [7]. In our series of 5 patients, three had existing PED. The significant number of PED could be attributed to the fact that PED has a recognized risk to tear from tangential stress in the detached tissues. It is possible that subfoveal PED causes elevation of the foveal retina and stretching of the photoreceptor layer by physical forces and thereby affecting the structural support of the fovea. This makes it more susceptible to vitreofoveal tractional forces, which can initiate a neurosensory retinal detachment and ultimately a FTMH [13]. Dynamic changes of flattening and recurrent distension of PED following injections could also possibly exacerbate the already unstable adhesion of vitreous and neuroretinal interface also rendering the PED more susceptible to macular hole formation. Oshima et al. reported a FTMH case following initial PED rip based on same theory but emphasized on perhaps the rapid contraction of retinal pigment epithelium as the exacerbating factor [8].

In summary, it is important for clinicians to be aware, that patients receiving intravitreal injections are at a small risk of developing complication such as a FTMH which is often unrecognised or under reported. The risk may perhaps be higher when treating CNVM in the presence of preexisting PED and or VMT. Based on our case series, both PED and VMT may be an important pre-existing contributory factor for FTMH separately or as a combined factor. Early recognition of this adverse effect and prompt consideration for vitreoretinal surgery may improve visual prognosis. With the recent introduction of Ocriplasmin [14] early recognition of VMT in particular, may also benefit from the challenging concept of treating any pre-existing VMT before intravitreal injection, to reduce the risk of FTMH.

\section{CONFLICT OF INTEREST}

The authors confirm that this article content has no conflict of interest.

\section{ACKNOWLEDGEMENTS}

Declared none.

\section{REFERENCES}

[1] Bressier NM, Boyer DS, Williams DF, et al. Cerebrovascular accidents in patients treated for choroidal neovascularisation with Ranibizumab in randomized controlled trials. Retina 2012; 32(9): 1821-8.

[2] Day S, Acquah K, Mruthyunjaya P, Grossman DS, Lee PP, Sloan FA. Ocular complications after anti-vascular endothelial growth factor therapy in Medicare patients with age-related macular degeneration. Am J Ophthalmol 2011; 152(2): 266-72.

[3] Kourlas H, Abrams P. Ranibizumab for the treatment of neovascular age related macular degeneration: a review. Clin Ther 2007; 29(9): 1850-61.

[4] Querques G, Souied EH, Soubrane G. Macular hole following intravitreal Ranibizumab injection for choroidal neovascular membrane caused by age-related macular degeneration. Acta Ophthalmol 2009; 87(2): 235-7.

[5] Clemens CR, Holz FG, Meyer CH. Macular hole formation in the presence of a pigment epithelial detachment after three consecutive intravitreal antivascular endothelial growth factor injections. J Ocul Pharmacol Ther 2010; 26(3): 297-9.

[6] Grigoropoulos V, Emfietzoglou J, Nikolaidis P, Theodossiadis G, Theodossiadis P. Full-thickness macular hole after intravitreal injection of ranibizumab in a patient with retinal pigment epithelium detachment and tear. Eur J Ophthalmol 2010; 20(2): 469-72.

[7] Cho JH, Park SE, Han JR, Kim HK, Nam WH. Macular hole after intravitreal ranibizumab injection for polypoidal choroidal vasculopathy. Clin Exp Optom 2011; 94(6): 586-8.

[8] Oshima Y, Apte RS, Nakao S, Yoshida S, Ishibashi T. Full thickness macular hole case after intravitreal aflibercept treatment. BMC Ophthalmol 2015; 15: 30.

[9] Gass JD. Idiopathic senile macular holes: Its early stages and pathogenesis. Retina 2003; 23(6 Suppl): 629-39.

[10] Gaudric A, Haouchine B, Massin P, et al. Macular hole formation: new data provided by optical coherence tomography. Arch Ophthalmol 1999; 117(6): 744-51.

[11] Geck U, Pustolla N, Baraki H, Atili A, Feltgen N, Hoerauf H. Posterior vitreous detachment following intravitreal drug injection. Graefes Arch Clin Exp Ophthalmol 2013; 251(7): 1691-5. 
[12] Duker JS, Kaiser PK, Binder S, et al. The International Vitreomacular Traction Study Group classification of vitreomacular adhesion, traction, and macular hole. Ophthalmology 2013; 120(12): 2611-9.
[13] Cazabon. S. Full- thickness macular hole formation associated with pigment epithelial detachment: link or coincidence? Int Ophthalmol 2010; 30: 739-42.

[14] Stalmans P, Duker JS, Kaiser PK, et al. Oct-based interpretation of the vitreomacular interface and indications for pharmacologic vitreolysis. Retina 2013; 33(10): 2003-11.

(C) Mukherjee et al.; Licensee Bentham Open.

This is an open access article licensed under the terms of the Creative Commons Attribution-Non-Commercial 4.0 International Public License (CC BY-NC 4.0) (https://creativecommons.org/licenses/by-nc/4.0/legalcode), which permits unrestricted, non-commercial use, distribution and reproduction in any medium, provided the work is properly cited. 